Original Research Article

\title{
Estimating the change in Forest Cover Density and Predicting NDVI for West Singhbhum using Linear Regression
}

\author{
Anand, Akash; Singh, Suraj Kumar; Kanga, Shruti \\ Centre for Land Resource Management, Central University of Jharkhand, Jharkhand, India. \\ Centre for Sustainable Development, Suresh Gyan Vihar University, Jaipur, India. \\ Centre for Climate Change and Water Research, Suresh Gyan Vihar University, Jaipur, India \\ Corresponding Author: shruti.kanga@mygyanvihar.com
}

\begin{abstract}
A R T I C L E I N F O
Received: 10 February 2018 | Accepted: 22 April 2018 | Published Online: 15 August 2018

DOI: $10.31786 / 09756272.18 .9 .1 .125$

EOI: $10.11208 /$ essence.18.9.1.125

Article is an Open Access Publication.

This work is licensed under Attribution-Non Commercial 4.0 International

(https://creativecommons.org/licenses/by/4.0/)

CThe Authors (2018). Publishing Rights @ MANU-ICMANU \& ESSENCE-IJERC.
\end{abstract}

\section{A B S T R A C T}

Forest Canopy Density (FCD) is defined as one of the key parameters to assess the ecological condition of a forest. The Present study deals with estimating the change in forest canopy density using remote sensing techniques for last decade i.e., from 2008 to 2018 of the West Singhbhum District. Biophysical models like Advanced Vegetation Index (AVI), Bare Soil Index (BI) and Canopy Shadow Index (SI) are overlaid to achieve the FCD for two time periods with an overall accuracy of $86 \%$ in 2008 and $82 \%$ in 2018. The final FCD is classified into five classes namely High forest, Moderate forest, Low forest, Wasteland, Bare land and it is evaluated how the High and Moderate forest is converting into Wastelands and Bare lands. The focus of this study is to assess the change in vegetation cover using NDVI and to predict the NDVI for year 2028 by generating linear regression model which has shown a coefficient of correlation of 0.617 . The derived results showed that how the high forest cover density is degrading in West Singhbhum and wastelands and bare lands are increasing linearly while this study showed the pattern of change in NDVI and predicted its scenario after one decade

\section{K E Y W O R D S}

Biophysical Parameters | Forest Canopy Density | NDVI | Landsat Image | Remote Sensing

\section{I T A T I O N}

Anand, Akash; Singh, Suraj Kumar; Kanga, Shruti (2018): Estimating the change in Forest Cover Density and Predicting NDVI for West Singhbhum using Linear Regression. ESSENCE Int. J. Env. Rehab. Conserv. IX (1): 193-203. 


\section{Introduction}

Forests are one of the world's most essential resources which presently intervened by humans that affects the ecological status of forest (Nandy et al., 2003). Forest Cover Density (FCD) is defined as the proportion of the coverage of forest floor by the vertical projection of peak of the tree and it is also known as crown coverage or canopy coverage of any area (Jenning et al., 1999 and Loi et al., 2017). Mapping, monitoring, and management of FCD is very critical for the sustainability of natural and ecological resources. Presently, the natural as well as anthropogenic factors are affecting the forest cover and that is affecting the FCD which causes the alteration of dense forests into moderately dense or fragmented forests. FCD modelling is carried out using a set of biophysical parameters namely, Advanced Vegetation Index (AVI), Bare Soil Index (BI), Canopy Shadow Index (SI) (Rikimaru et al., 2002 and Roy et al., 1997). Classification scheme of Forest Survey of India (FSI) is applied in present study which classifies the forest canopy into five classes, that are dense forest cover for canopy coverage more than $70 \%$, between $40 \%-70 \%$ for moderate forest cover, between $10 \%-40 \%$ is termed as low or open forest cover while canopy density lesser than $10 \%$ are called scrubland and others are classified as bare lands (FSI, http://fsi.nic.in/details.php? pgID=sb_8).

Satellite based Remote Sensing provides a synoptic approach for monitoring the land use land cover features on a temporal basis and it is playing an important role in assessing the forest cover changes. (Lillesand et al., 1994). The ability of satellite imageries to provide an accurate information about the local, regional as well as the global land use and land cover is endorsed in many recent studies (Kanga et al., 2014 and Ranjan et al., 2016). Atmospheric corrections are usually applied to every satellite imagery to eliminate the atmospheric interferences like scattering and absorption phenomenon in the atmosphere by aerosols, water droplets and other atmospheric molecules on satellite data. Atmospheric correction used primarily to calculate the vegetation indices like NDVI which uses reflectance of red and near infrared bands (Xie et al., 2010). Linear Regression is also one of the tool in remote sensing which is broadly used to establish a relation between two variables by fitting a linear equation in which one variable is dependent variable and another is independent variable. Linear Regression is commonly used for the prediction with the established linear relation between past datasets.

Normalized Differential Vegetation Index (NDVI) is one of the crucial vegetation index which is widely used to measure vegetation health over an area. NDVI is used to assess the change in vegetation at a very high temporal resolution over regional as well the global platform. It is calculated as a ratio of difference in reflectance of Red and Near Infrared bands and sum of Red and Near Infrared bands (Nageswara et al., 2005). NDVI values varies between -1 to +1 where the negative values shows bare soil, wasteland, snow and waterbody and the positive value indicated the vegetation covers like sparse vegetation, cropland, open forest and dense forest. In present study, NDVI is calculated and classified into five classes for better precision. Likewise, Shilong (2003) analyzed the inter annual variation in NDVI and their relationship between climatic variables in which the NDVI is classified into six classes to show the trends of NDVI in recent past and the impacts of urbanization and agricultural practices on vegetation cover (Piao et al., 2003). Whereas Meera (2015) used threshold values for the NDVI such as $0.1,0.15,0.2,0.25,0.3,0.35,0.4$ and 0.5 and concluded that vegetation analysis are helpful for the policymakers and to male predictions to figure out the future scenarios as well (Gandhi et al., 2015).

Forest cover is decreasing throughout the globe due to various natural and anthropogenic activities, in which geospatial technology plays a very crucial role in monitoring the forest cover. The present investigation is an attempt to show the trend of forest canopy change in West Singhbhum and to establish a relation between the land cover features like wastelands and bare lands. The role of remote sensing and GIS is also defined to study 
the alteration in ground based features like vegetation, land cover classification, topography, water resources and urban area (Gandhi et al., 2015).

Study Area: West Singhbhum district is bifurcated from the old Singhbhum district in the year 1990 and currently, it is spread over $21^{0} 58^{\prime}$ to $23^{0} 36^{\prime}$ north and $85^{\circ} 0^{\prime}$ to $86^{0} 54^{\prime}$ east. This District has 15 blocks with two administrative subdivisions and present study area covers a geographical area of 990.84 Sq. $\mathrm{Km}^{2}$ and total vegetation coverage are $26.7 \%$ of the geographical area (West Singhbhum District Profile: http:// www.jharkhand.gov.in/web/west-Singhbhum/ district-profile ).

Fig.1: Study Area
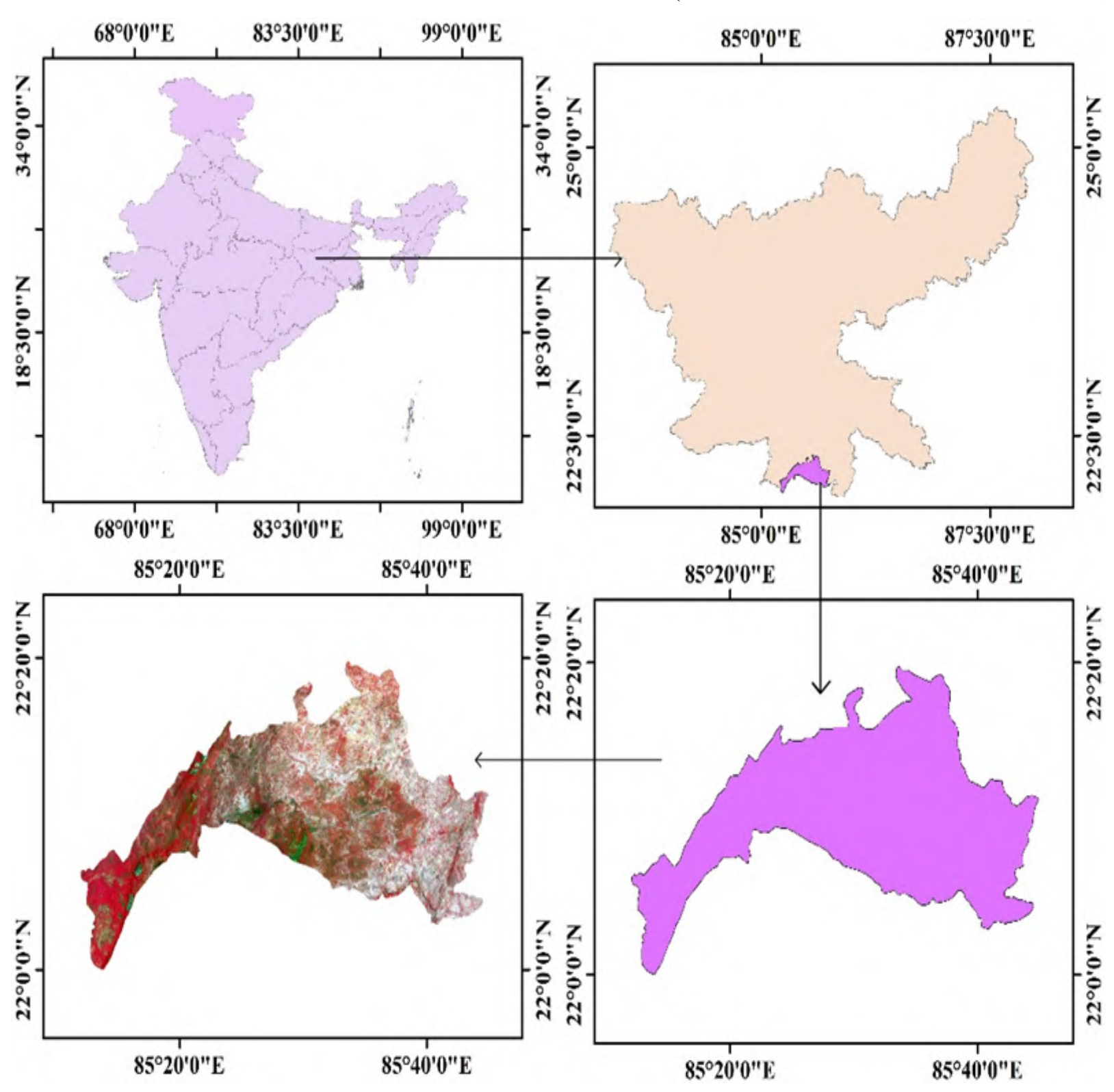

The study area is mostly covered with deep forest, mountains, steep slopes, waterfalls and this area is also known worldwide for its best quality of Sal forests. Elephants, tigers, bear, wild dogs are local fauna of this region. West Singhbhum contains one of the largest iron ore deposits in India. The climatic conditions in this region are very pleasing and the annual average rainfall in this district is approximately $1422 \mathrm{~mm}$. This district contains 10.4\% of its total area as protected forest and has three main soil groups as rocky soil which is found in southern and western part of district, black soil is found in the wetlands of Kolhan whereas the red soil is found throughout the district (Ground Water Information Booklet, 


\section{Materials and Methods}

Data and Software Used: Present investigation is done to investigate the FCD for last one decades of the study area, for which two Landsat images were acquired for the year 2008 and 2018 from United States Geological Survey (USGS) (United State Geological Survey, http://glovis.usgs.gov/). Topographic sheets of the study area is acquired from India and Pakistan AMS topographic sheets at a scale of 1:50,000 (India and Pakistan AMS topographic maps. http://www.lib.utexas.edu/ map.ams/india/nf-45-01). All the images that were acquired are cloud free and having UTM WGS84 projection system. Image preprocessing is done in ERDAS IMAGINE and image analysis and raster calculations are performed using ArcMap software.

Image Normalization: Image normalization is done to remove the distortion caused by variation in sun's azimuth, sensor's response, and atmospheric conditions (Banerjee et al., 2014). It is a pre-processing technique which rectifies the distortions in the reflectance of surface features and makes the image organized for analysis purposes. Normalization can be performed in two different ways, absolute and relative normalization. In absolute normalization, they rectify the bias caused by the physical environment but in relative normalization, a reference image is used to rectify the other images, it is widely used to analyze the land use land cover changes and the vegetation indices (Vorovencii et al., 2014).

DN to Radiance Conversion: The Rate of transfer of energy at the sensor, per square meter on ground, for a unit solid angle per unit wavelength, is known as a spectral radiance and the term radiance refers to the total radiation upwelling from the earth to the sensor. DN is converted to the Radiance by considering some rescaling factors which are obtained from the metadata of satellite imagery. DN to Radiance is converted using Equation 1.

$$
\begin{aligned}
\mathrm{L}_{\lambda}= & \left(\operatorname{LMAX}_{\lambda}-\mathrm{LMIN}_{\lambda} / \mathrm{Q}_{\text {calmax }}-\mathrm{Q}_{\text {calmin }}\right)^{*} \\
& \left(\mathrm{Q}_{\text {cal }}-\mathrm{Q}_{\text {calmin }}\right)+\operatorname{LMAX}_{\lambda}
\end{aligned}
$$

Where, $\mathrm{L}_{\lambda}=$ Spectral Radiance in $\mathrm{W} /(\mathrm{m} 2 \mathrm{sr} \mu \mathrm{m})$ $\mathrm{Q}_{\text {cal }}=$ Quantized Calibrated DN value $\mathrm{Q}_{\text {calmin }}=$ Minimum quantized calibrated pixel value

$\mathrm{Q}_{\text {calmax }}=$ Maximum quantized calibrated pixel value

LMIN $_{\lambda}=$ Spectral radiance that is scaled to Qcalmin

$\operatorname{LMAX}_{\lambda}=$ Spectral radiance that is scaled to $\mathrm{Q}_{\text {cal- }}$ $\max$

Radiance to Top of Atmosphere Reflectance (TOA) Conversion: Reflectance is simply the ratio of radiation coming from the sun and radiation coming from the earth surface. It is measured on a scale of 0 to 1 . Radiance to TOA Reflectance conversion requires some additional information like sun distance from earth, solar zenith angle and exoatmospheric irradiance to put in the equation. Mathematically, Reflectance can be calculated using Equation 2.

$\mathrm{P} \lambda=\pi . \mathrm{L} \lambda . \mathrm{d} 2 / \operatorname{ESUN} \lambda \cdot \cos \theta \mathrm{s}$

Where, $\mathrm{P}_{\lambda}=$ Top of Atmosphere Reflectance $\pi \quad=\quad \begin{array}{lllllll}\pi & & 1 & 4 & 1 & 5 & 9\end{array}$ $\mathrm{L}_{\lambda}=$ Spectral Radiance in W/ $(\mathrm{m} 2 \mathrm{sr} \mu \mathrm{m})$ $\mathrm{d}=$ Distance between Earth and Sun $\operatorname{ESUN}_{\lambda}=$ Mean exoatmospheric solar irradiance $\mathrm{i} \mathrm{n} \quad \mathrm{W} /\left(\begin{array}{ccc}\mathrm{m}^{2} & \mu \mathrm{m}\end{array}\right)$ $\theta \mathrm{s}=$ Solar Zenith Angle in degree/radians.

\section{Advanced Vegetation Index (AVI):}

AVI is calculated to assess the status of vegetation in the forest and delineate the subtle changes in canopy density which cannot be assessed by NDVI. Both the NDVI and AVI are calculated using red and near Infrared bands but the power degree in AVI increase its sensitivity towards forest canopy. Generally, AVI highlights the high forest canopy and the grasslands of any region and shows lower values to bare lands. If the value of near infrared is less than the red band then the value of $\mathrm{AVI}=0$, otherwise Equation 3 is used to calculate AVI. 
Author (s)

$$
\mathrm{AVI}=\{(\mathrm{B} 4+1) \times(256-\mathrm{B} 3) \times(\mathrm{B} 4-\mathrm{B} 3)]^{1 / 3}
$$

Where B4 = Near Infrared Band

$\mathrm{B} 3=$ Red Band

Bare Soil Index (BI): BI is calculated to categorize agricultural and non-agricultural vegetation for a given area. It is computed using shortwave infrared band which enhances the bare soil property of a land and red and infrared bands includes the vegetation property to the index (Duy et al., 2012). BI shows a higher value to the bare lands and lower values to the vegetation and forest covers. By combining bare soil condition and vegetation properties, we can assess the exposed soil conditions. Mathematically, it is calculated by using Equation 4.

$\mathrm{BI}=\{(\mathrm{B} 5+\mathrm{B} 3)-(\mathrm{B} 4+\mathrm{B} 1)\} /\{(\mathrm{B} 5+\mathrm{B} 3)-(\mathrm{B} 4+$ $\mathrm{B} 1)\} * 100+100$

Where B1 = Blue Band

B5 $=$ Shortwave Infrared Band

Canopy Shadow Index (SI): SI is computed using the low radiance of visible bands to extract the three dimensional structures of the forest. It depends on the arrangement of trees in the forest, and the younger plants have low radiance than mature trees (Pandian et al., 2016). Because SI depends on the arrangement of trees and canopy cover, it shows higher values to the forest canopy and lesser value to bare lands and grasslands. Visible bands are used to define the shadow index using Equation 5.

$$
\mathrm{SI}=((256-\mathrm{B} 1) *(256-\mathrm{B} 2) *(256-\mathrm{B} 3)) 1 / 3
$$

The value of SI increases with the increasing value of FCD because when FCD increase with the increase in crown cover and denser crown cover generate higher SI value.

Forest Canopy Density (FCD): FCD is one of the essential parameters for examining the forest cover conditions and to monitor the transformation in forest during forestry activities that may include the degradation or rehabilitation of procedure for FCD calculation by assigning weights to the calcu-
ESSENCE-IJERC (2018)

lated biophysical factors that are AVI, BI and SI for the FCD calculation. FCD is calculated for the forest region. The flowchart in Figure 2 shows the year 2008 and 2018 to see the changes in forest canopy cover for last one decade. Satellite image for both the years are radiometrically calibrated and then the indices were calculated using the respective equations and lastly weight is assigned to each index to get the result. It has been classified into five classes namely high forest, moderate forest, low forest, grassland and bare lands and the areas have been calculated to see the change in FCD between 2008 and 2018. To analyze the quantitative variation in different FCD classes and to see the exact change in forest cover density, area calculation is done for each features class in raster calculator using ArcGIS.

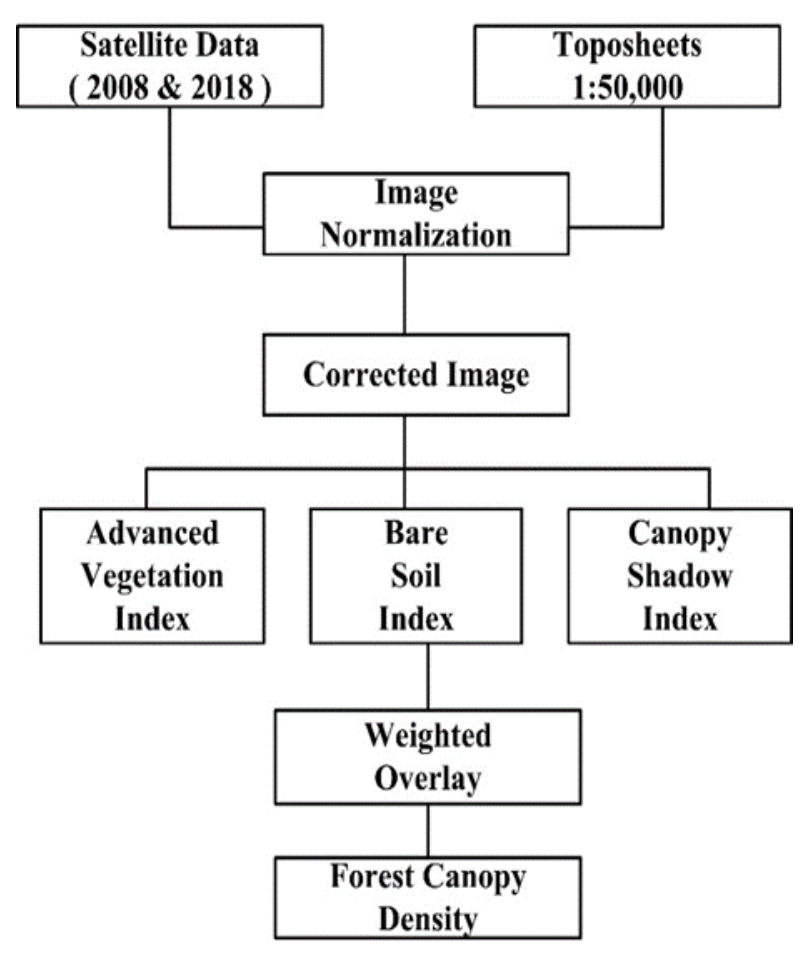

Fig.2: Flowchart for FCD Calculation

\section{Normalized Differential Vegetation Index} (NDVI): NDVI is one of the common and most widely used vegetation index for estimating global as well as regional variations in vegetation cover (Bhandari et al., 2012). NDVI is calculated by the ratio of difference in the near-infrared band and red band by the sum of the near-infrared and red band (Richardson et al., 1992), as shown in Equation 6. 


$$
\text { NDVI }=\left(\begin{array}{l|}
(\text { NIR }- \text { Red }) \\
(\text { NIR }+ \text { Red })
\end{array}\right.
$$

The value of NDVI lies between -1 to +1 in which the positive value indicates the vegetation cover and negative values shows barren lands, snow, rocks, sand etc.

Linear Regression Model: Linear Regression is widely used to establish a relation between two variables. It takes one variable, checks its variation with another variable and gives a linear equation to exhibit relationship (Palmate et al., 2017). In present study, linear regression is performed using curve fitting tool in MATLAB software to establish a relation between the NDVI of 2008 and 2018. Through the generated linear regression equation, the prediction for NDVI of 2028 is done in raster calculator of ArcGIS software.

\section{Result and Discussion}

Biophysical Parameters: Biophysical parameters like AVI, SI, and BI is calculated for year 2008 and 2018 of the study area. In this analysis, each biophysical element is classified into five classes according to their values namely very low, low, moderate, high and very high. It has been observed that the higher values of BI show the bare lands of the regions whereas the lower values show the forest cover and grasslands. . In AVI the conditions are very different from BI, here the higher value demarcates the dense forest cover and grasslands beside the bare lands are shown by the lower
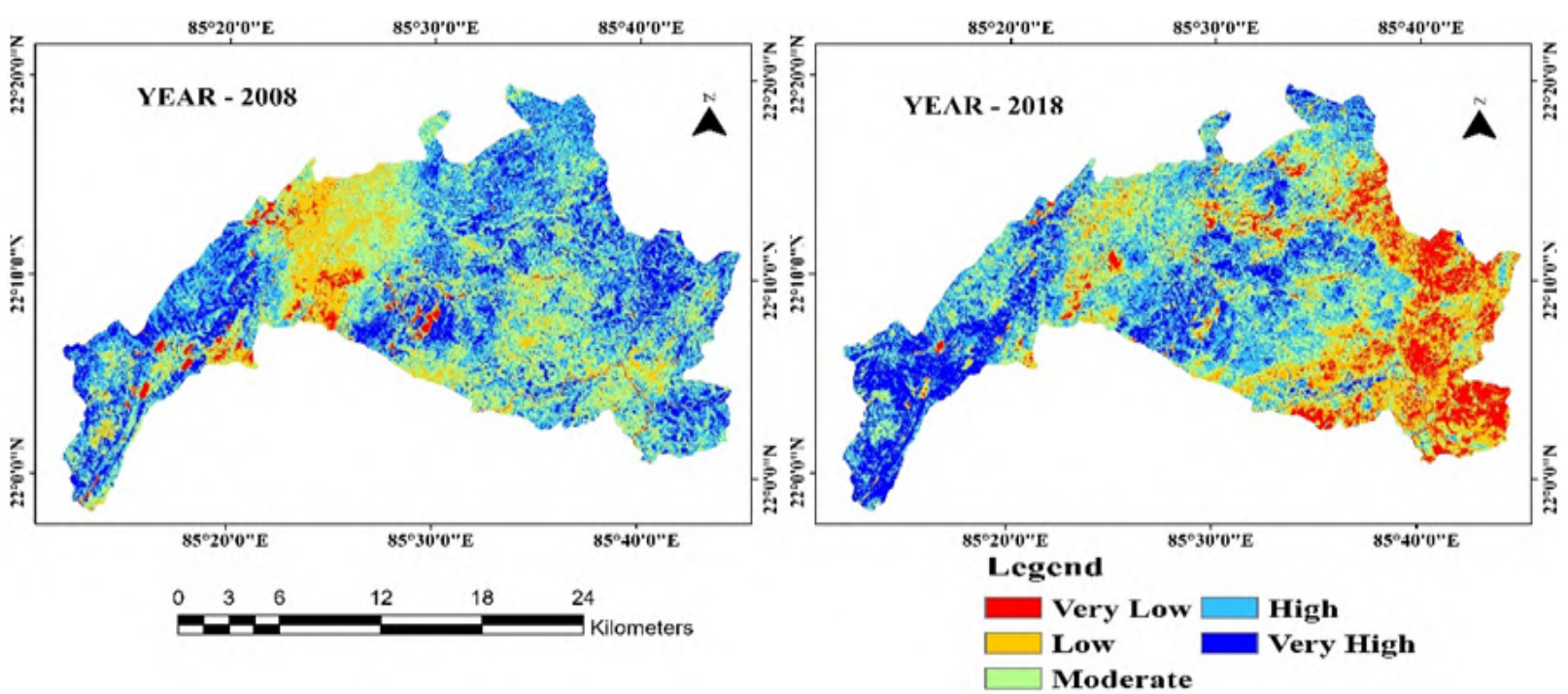

Fig.3: Bare Soil Index of West Singhbhum
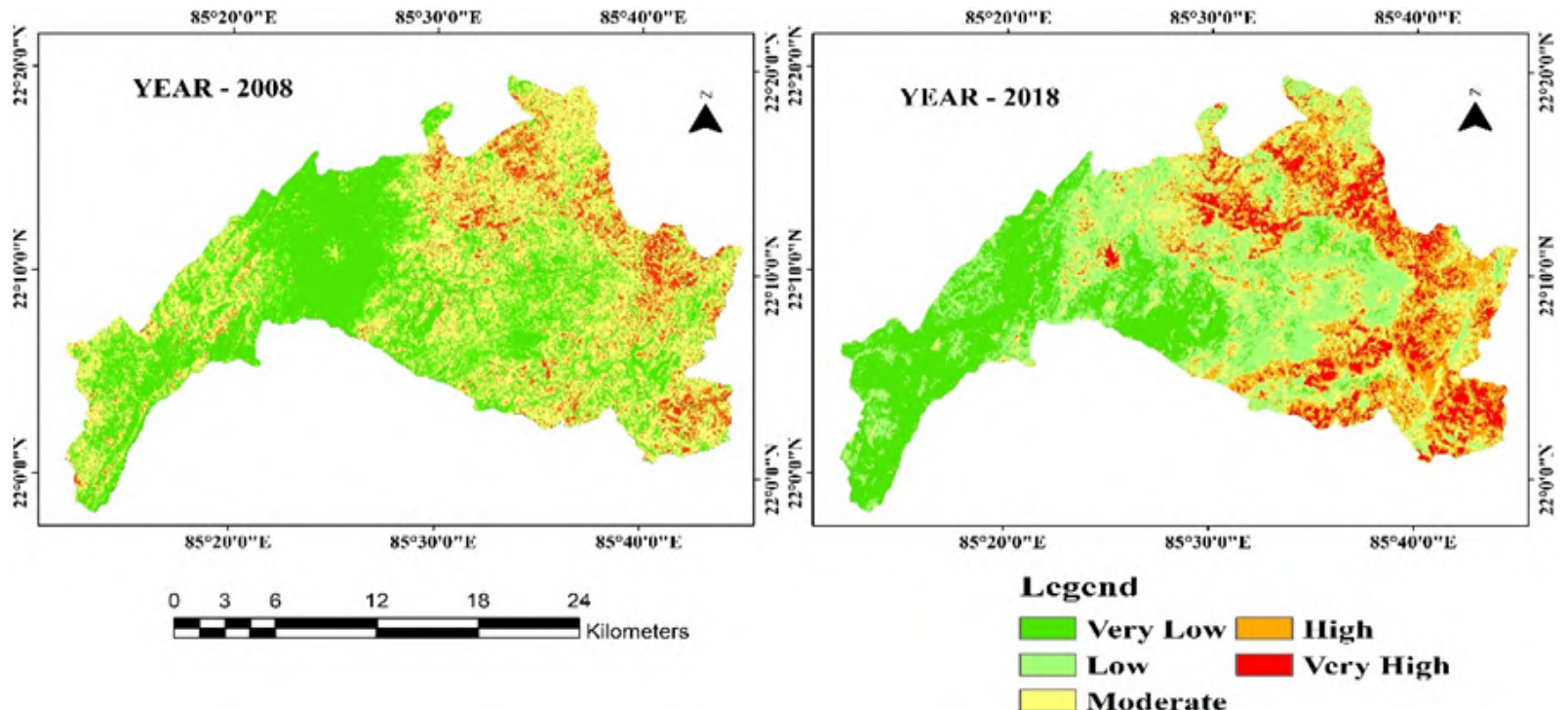

Fig.4: Advanced Vegetation Index of West Singhbhum 
values of AVI. Similarly, in SI, dense forest cover and the open forests shows higher

values but unlike from AVI, it shows lower values to the grasslands as well as the bare lands because the grasslands didn't generate canopy cover as the dense forests do, so SI shows lower values to grasslands and bare lands.values but unlike from AVI, it shows lower values to the grasslands as well as the bare lands because the grasslands didn't generate canopy cover as the dense forests do, so SI shows lower values to grasslands and bare lands.
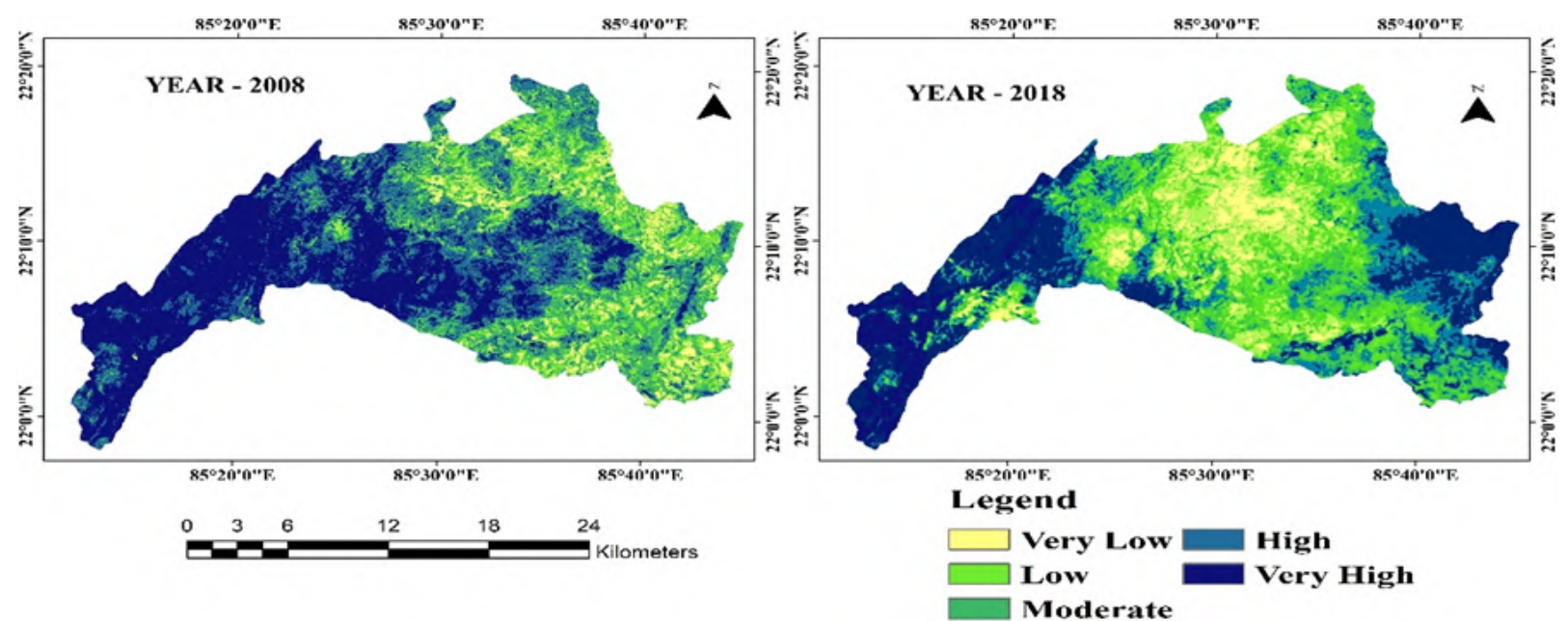

Fig.5: Canopy Shadow Index of West Singhbhum

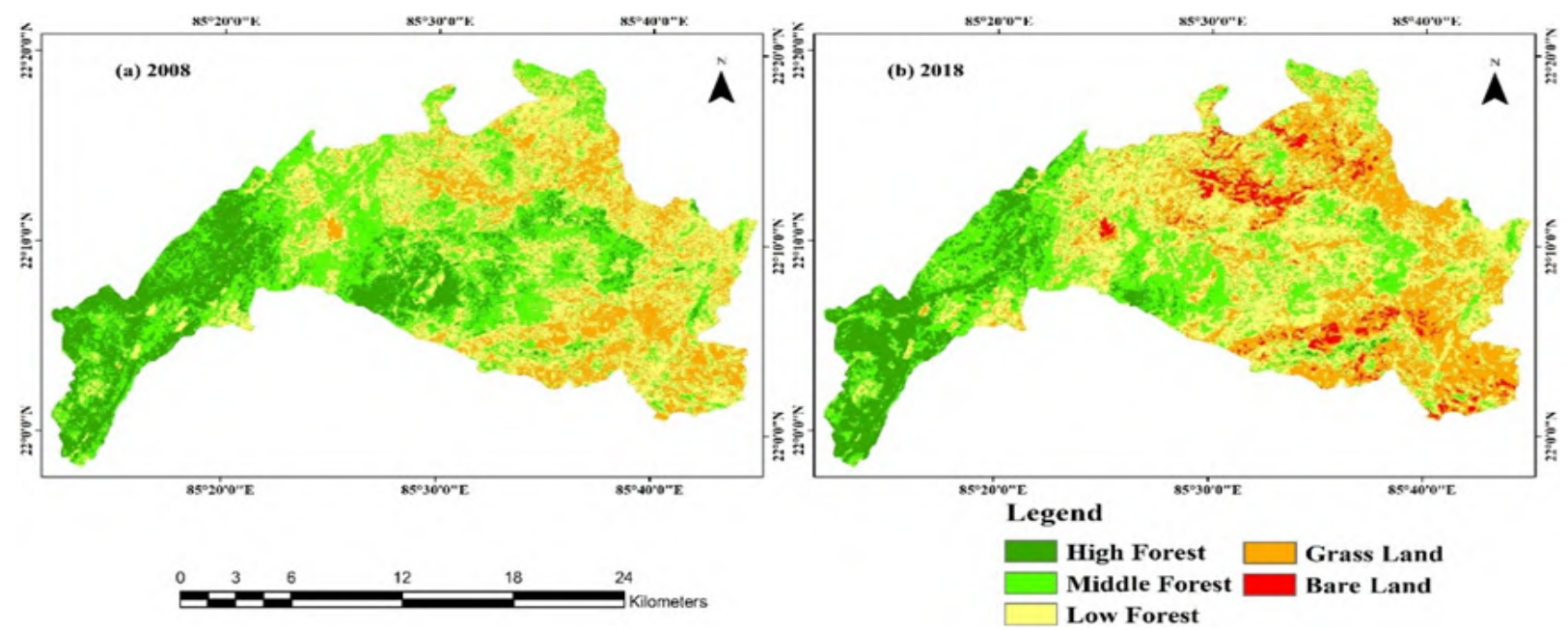

Fig.6: Forest Canopy Density Map for year 2008 and 2018

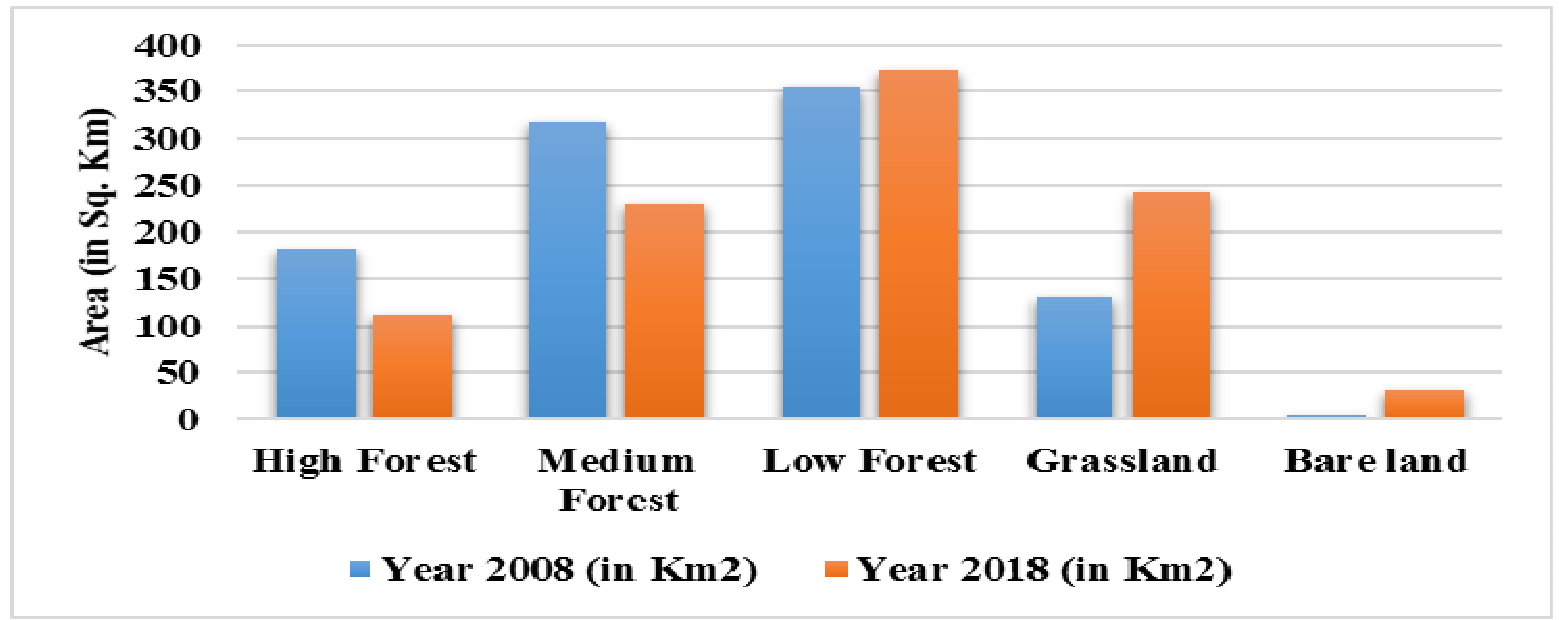

Fig.7: Graphical Representation of FCD for year 2008 and 2018 
Figure 6 shows the FCD for year 2008 and 2018 of the study area, in which it has been observed that the high forest cover is decreasing very drastically, the high forest cover has been decreased from $181.079 \mathrm{~km} 2$ in 2008 to $111.593 \mathrm{~km} 2$ in 2018 whereas the medium forest cover has been decreased from $317.768 \mathrm{~km} 2$ to $229.496 \mathrm{~km} 2$ respectively. With the decrease in high and medium forest cover, the bare lands and grasslands are increasing significantly. Quantitative analysis reveals that high forest cover was decreased by $38.37 \%$ in the last decade whereas the low forest and grasslands are increased by $5.18 \%$ and $46.25 \%$ respectively. Bare land in 2008 is observed to be $6.083 \mathrm{~km} 2$ that got increased significantly to $31.743 \mathrm{~km} 2$ in 2018 .

Accuracy Assessment: To assess the accuracy of calculated FCD since 2008 and 2018, an error

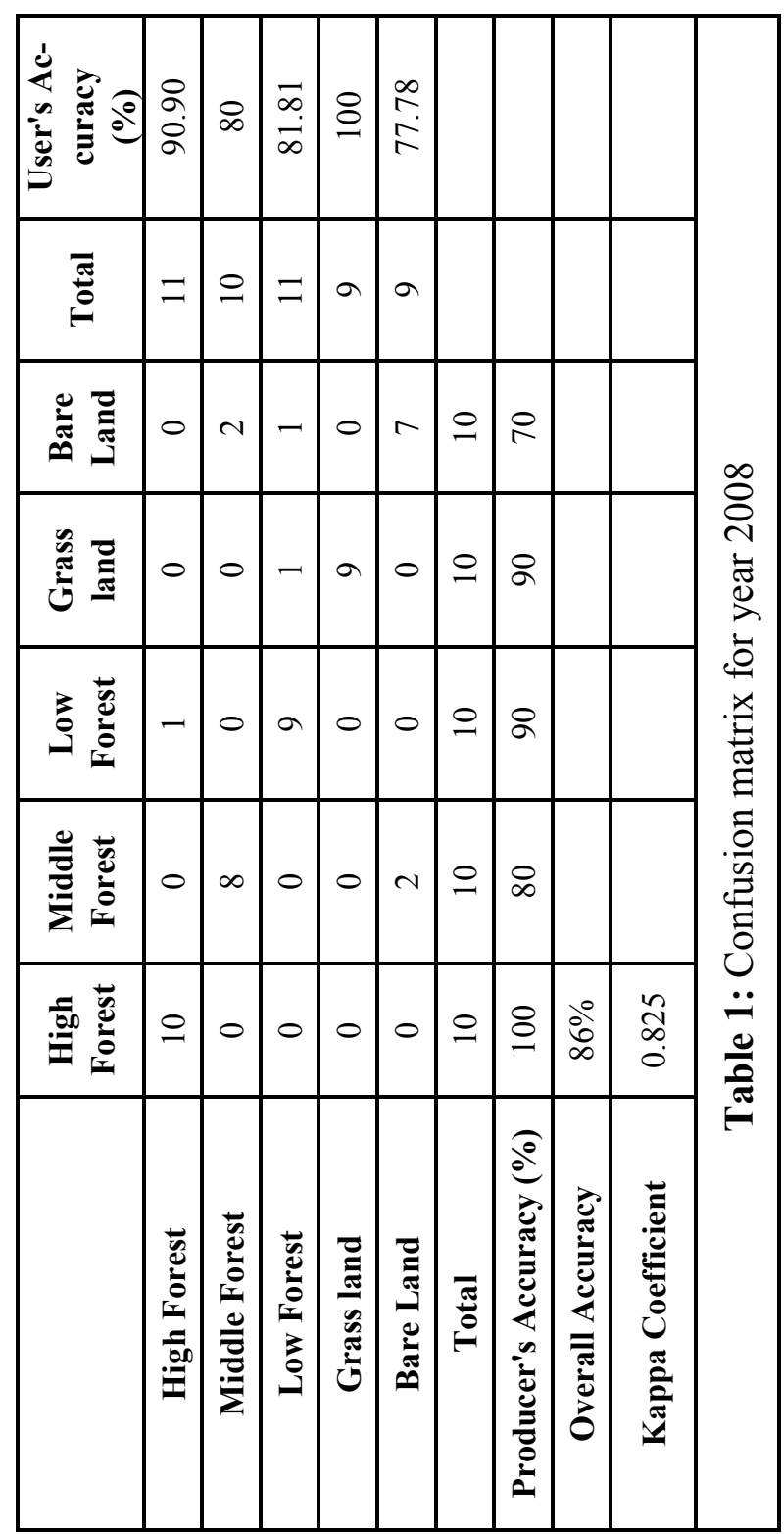

matrix is prepared using classified FCD and pre classified satellite imagery (Banko et al., 1998 and Ranjan et al., 2017). Confusion matrix is prepared by selecting on screen 10 random pixels from the satellite image for each class by following the interpretation rules. It is obtained from the accuracy assessment that, in FCD of 2008, the overall accuracy is $86 \%$ and kappa coefficient is 0.825 whereas in FCD of 2018, the overall accuracy is found to be $84 \%$ and kappa coefficient is 0.8 . The confusion matrix for FCD of year 2008 and 2018 are displayed in Table 2 and Table 3 respectively.

\begin{tabular}{|c|c|c|c|c|c|c|c|c|c|c|}
\hline 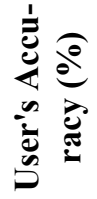 & $\approx$ & 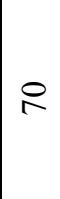 & 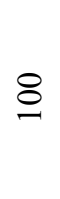 & 8 & ڤે & & & & & \\
\hline 苞 & $\simeq$ & 으 & $\infty$ & $r$ & 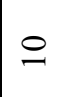 & & & & & \\
\hline 离 & 0 & 0 & 0 & 0 & $\circ$ & $\circ$ & 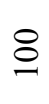 & & & \\
\hline 总 & $N$ & - & 0 & $r$ & 0 & $ㅇ$ & 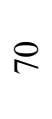 & & & $\stackrel{\infty}{\approx}$ \\
\hline$\dot{b}_{0}^{\dot{0}}$ & 0 & N & $\infty$ & 0 & 0 & $\bigcirc$ & $\infty$ & & & 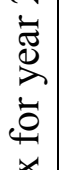 \\
\hline 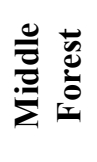 & - & $r$ & 0 & 0 & $\sim$ & $ㅇ$ & $\stackrel{2}{2}$ & & & 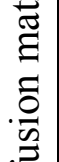 \\
\hline 可 & $a$ & 0 & 0 & 0 & - & 으 & \& & 仓ें & $\stackrel{\hat{0}}{0}$ & $\begin{array}{l}0 \\
\ddot{\lambda} \\
0\end{array}$ \\
\hline & 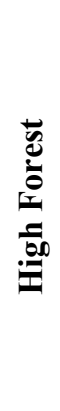 & 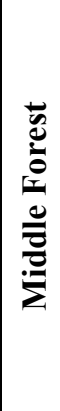 & 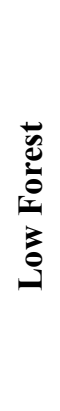 & 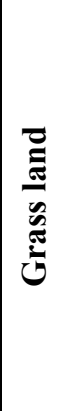 & 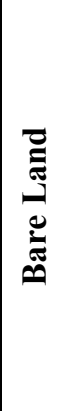 & 产 & 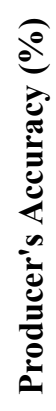 & 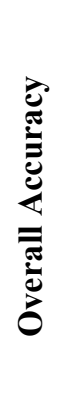 & 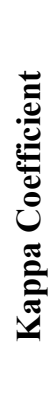 & \\
\hline
\end{tabular}


Predicted NDVI: NDVI for year 2008 and 2018 is calculated and classified into five classes according to their values that is less than $0.10,0.10$ to $0.20,0.20$ to $0.30,0.30$ to 0.40 and greater than 0.40 . Here, the values less than 0.10 shows features like water, bare lands and rocks. Whereas the moderate values shows grasslands and scrubland and the values greater than 0.40 shows open forests and dense forests. Presently, it is estimated that the dense forest are degrading gradually and converting into open forest or grasslands due to the gradual increments in the human popu-
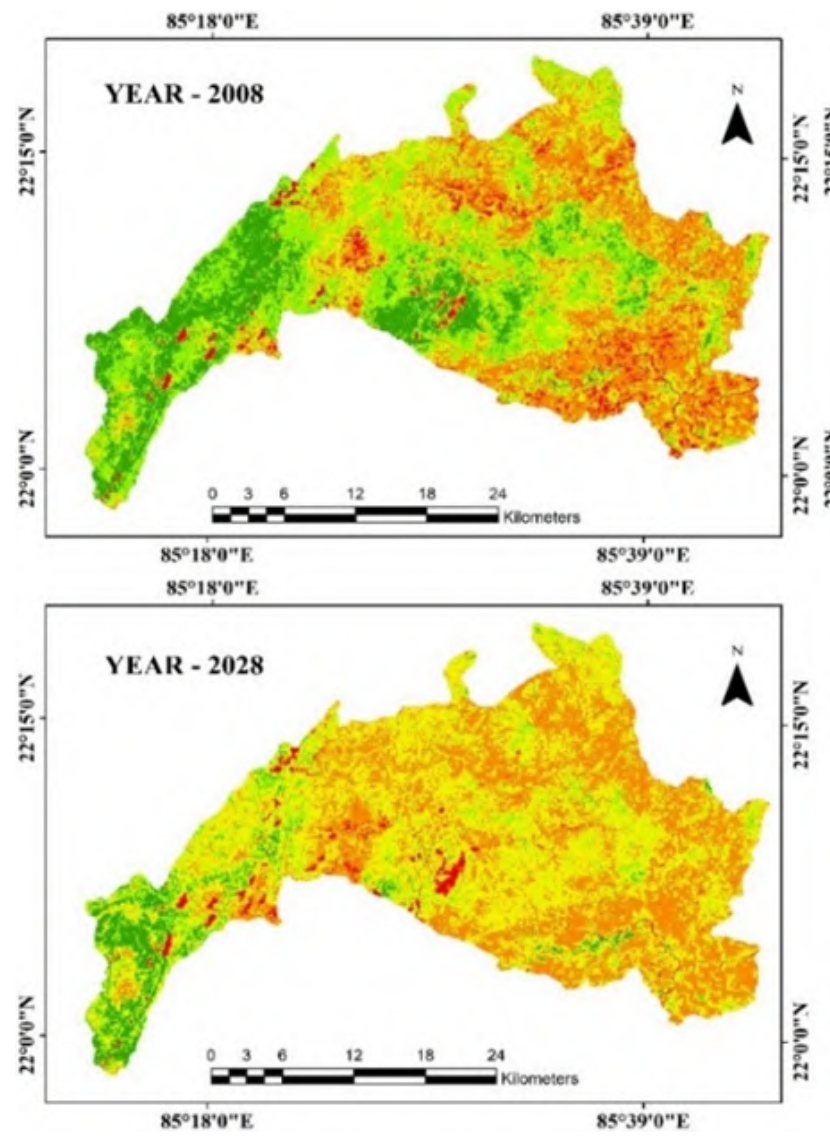

gradually converting into grasslands and bare land in the study area.

\section{Conclusion}

In this study, the analysis is done to understand the changes in forest canopy density from 2008 to 2018 using three biophysical parameters namely AVI, SI and BI. The result illustrates that the forest cover density of the study area is drastically decreasing and the forest covers are converting into grasslands or bare lands. Furthermore, to demonstrate the variation in vegetation cover, NDVI for two time periods are

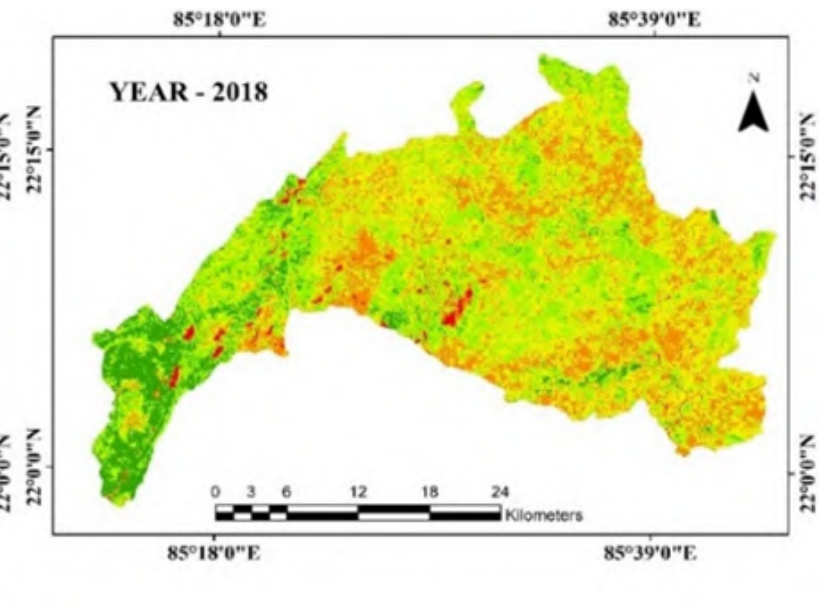

Legend

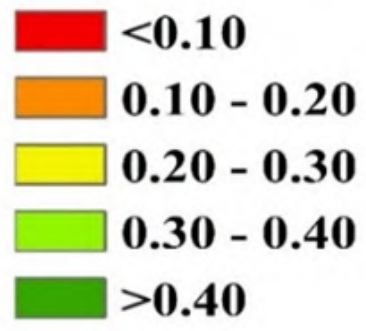

Figure 7 NDVI for year 2008 and 2018 and predicted NDVI for year 2028

lation in the area.

Prediction is made for the NDVI using the correlation of pixel wise NDVI values of 2008 and 2028 and a R2 value of 0.617 is observed with a RMSE value of 0.0463 . Qualitative analysis of predicted NDVI depicts that if the rate of degradation of dense forest cover continues then the scenarios in the future will be much worst. It has been observed that the dense and open forests are calculated and it has been qualitatively concluded that the vegetation cover has changed extremely in past decade. A prediction of NDVI is made for the year 2028 using linear regression with a R2 value of 0.617 that has shown an extreme change in forest cover of the present study area. Lastly, it is concluded that Geoinformatics Technology has a wide aspect in calculating the recent changes in regional as well as global forest cover and to pre- 
dict the future scenarios for the same.

\section{Acknowledgment}

The authors are thankful to the United States Geological Survey for providing Satellite data; Reviewers for their valuable comments which increased the quality of manuscript and Suraj Kumar Singh (Supervisor/Mentor) for guidance the research work.

\section{References}

Bhandari, A. K. and Kumar, A. (2012): Feature Extraction using Normalized Difference Vegetation Index (NDVI): A Case Study of Jabalpur City. Proceedings of Communication, Computing \& Security. Procedia Technology, (6): 612- 621.

Banerjee, K. (2014): Forest Canopy Density Mapping Using Advance Geospatial Techniques. International Journal of Innovative Science, Engineering \& Technology, 1(7): 358-363.

Banko, G. (1998): A Review of assessing the accuracy of classification of remotely sensed data and methods including remote sensing data in forest inventory. Int Inst for Appl Syst Anal- Inter Rep. 119: 270-279.

Duy, N. B. (2012): Study on vegetation indices selection and changing detection thresholds selection in Land cover change detection assessment using change vector analysis. International Congress on Environmental Modelling and Software Managing Resources of a Limited Planet, Sixth Biennial Meeting, Leipzig, Germany.

Forest Survey of India (FSI), Forest Cover Classification scheme, Available at: http:// fsi.nic.in/details.php?pgID=sb_8

Gandhi, M. (2015): Ndvi: Vegetation change detection using remote sensing and gis - A case study of Vellore District. 3rd International Conference on Recent Trends in Computing, pp $1199-1210$.

Ground Water Information Booklet (2013): West Singhbhum District, Jharkhand, Central Ground Water Board, Ministry of Water Resources, Govt. of India.

India and Pakistan AMS topographic maps.
Available at: http://www.lib.utexas.edu/ map.ams/india/nf -45-01

Jenning, S. B.; Brown, N. D. and Shell, D. (1999): Assessing forest canopies and understory illumination: Canopy closure, canopy cover and other measures. Journal of Forest, 72(1): 59-73.

Kanga, S.; Sharma, L. K.; Pandey, P. C. and Nathawat, M. S. (2014): GIS Modelling approach for forest fire risk assessment and management. International Journal of Advancement in Remote Sensing, GIS, and Geography, 2(1): 30-44.

Lillesand T. M. and Kiefer R. W. (1994): Remote Sensing and Image Interpretation. 3rd edition, John Wiley and Sons, New York, USA.

Loi, D. T. (2017): Integration of GIS and Remote Sensing for Evaluating Forest Canopy Density Index in Thai Nguyen Province,

Vietnam. International Journal of Environmental Science and Development, 8(8): 539-542.

Nageswara, P. P. R.; Shobha, S. V.; Ramesh, K. S. and Somashekhar, R. K. (2005): Satellite based assessment of Agricultural drought in Karnataka State. Journal of the Indian society of remote sensing, 33(3): 429-434.

Nandy, S. (2003): Forest Canopy Density Stratification Using Biophysical Modeling. Journal of the Indian Society of Remote Sensing, 31 (4): 291 - 297.

Palmate, S. S. (2017): Climate change impact on forest cover and vegetation in Betwa Basin, India. Appl Water Sci., 7: 103-114.

Pandian, M. (2016): Forest Canopy Density and ASTER DEM based Study for Dense Forest Investigation using Remote Sensing and GIS Techniques. International Journal of Research in Environmental Science and Technology, 6(1): 1-4.

Piao, S. (2003): Interannual variations of monthly and seasonal normalized difference vegetation index (NDVI) in China from 1982 to 1999. Journal of Geophysical Research, 108 (14): 1-13.

Ranjan, A. K.; Anand, A.; Kumar, P.B.S.; Verma, S.K. and Murmu, L. (2017): Prediction of 
Land Surface Temperature Using Artificial Neural Network in Conjunction with Geoinformatics Technology in Sun City Jodhpur (Rajasthan), India. Asian Journal of Geoinformatics, 17(3): $14-23$.

Ranjan A. K., Anand A., Vallisree, S. and Singh R.K. (2016): LU/LC change detection and forest degradation analysis in Dalma Wildlife in Jamshedpur-India. Aims Geosciences, 2(4): 273-285.

Richardson, A. and Everitt, J. (1992): Using Spectral Vegetation Indices to Estimate Rangeland Productivity. Geocarto International, 1: 6377.

Rikimaru, A.; Roy, P.S. and Miyatake, S. (2002): ropical forest cover density mapping. Tropical Ecology, 43(1): 39-47.

Roy, P.S.; Miyatake, S. and Rikimaru, A. (1997): A Biophysical spectral response modeling approach for forest density stratification. Proceedings of the 18th Asian conference on remote sensing.

United State Geological Survey. Available at: http://glovis.usgs.gov/.

Vorovencii, Iosif and Muntean, D.M. (2014): Relative radiometric normalization methods: overview and an application to Landsat images. Journal of Geodesy and Cadaster, pp 193-200.

West Singhbhum District Profile, Government of Jharkhand Available at: http:// www.jharkhand.gov.in/web/west-singhbhum/ district-profile

Xie, Y.; Zhao, X.; Li, L.L. and Wang, H. (2010): Alculating NDVI for landsat7-ETM data after atmospheric correction using $6 \mathrm{~S}$ model: $\mathrm{A}$ case study in Zhangye City, China.18th International Conference on Geoinformatics, Peking University, Beijing, China, June. 1-4. 